\section{What did Heisenberg know?}

SIR - Regarding the question of how much Werner Heisenberg knew about the explosion of the atomic bomb (book review by Irving M. Klotz, Nature 379, 411; 1996), I have a - possibly exaggerated - statement by him in his own handwriting. In Germany and Austria, there was a rumour after the dropping of the bombs on Japan that Nazi Germany had invented the atomic bomb but had not used it and that the Americans had appropriated this German "miracle weapon".

Although this was clearly untrue, I took the opportunity of a visit by Heisenberg to Vienna in the early 1950 s to interview him and to write an article entitled "Professor Heisenberg: Hitler's Germany had no atomic bomb. An authoritative statement by the head of German atomic research". (I was at the time science editor of the Viennese newspaper ArbeiterZeitung.)

Heisenberg checked my copy but changed hardly anything, because, on his advice, I had based my article on a paper by him in Die Naturwissenschaften (33, 325; 1946). But at one place he added a sentence that reads: "Man wusste aber in Deutschland, wie man die Atomenergie im 'Reaktor' zum Betrieb von Maschinen verwenden kann, man wusste auch, dass im Reaktor der Sprengstoff Plutonium (der in Deutschland nicht so hiess) gewonnen werden kann, aus dem Atombomben gemacht werden." ("But it was known in Germany how [the] atomic energy from the 'reactor' can be used for the running of machines; it was known too that the explosive plutonium (which in Germany was not known by that name) of which atomic bombs are made can be generated in the reactor.") Heisenberg wanted to add something further but crossed out the first word.

Contrary to Heisenberg's statement and as Irving M. Klotz says in his book review, it is doubtful whether much was known about plutonium in Nazi Germany. In 1944 (with a preface dated September 1943), the book Einführung in die Kernphysik by Wolfgang Riezler was published in Leipzig. As the text on transuranium elements on page 161 shows, a small quantity of element 93 (neptunium) had been produced, but element 94 (plutonium) had not yet been isolated:

Irradiating uranium with a strong neutron source, it was possible to produce enough of the element 93 from $\mathrm{U}^{239} \ldots$

The nucleus $93^{239}$ also is a beta-emitter with a halflife of 2.3 days. It must trans-

form, therefore, by its radiation to an isotope of element 94. It was not possible, however, to discover radiation related to this new nucleus although uranium was exposed for a whole year to very strong neutron radiation produced by means of a cyclotron It is therefore supposed that this new nucleus is a very long-living radioactive substance, probably an alpha-emitter. Its life-span has to be more than a million years [in fact, it is 24,390 years, E.K.], otherwise its alpharadiation would have been detected by now.

Of course, secret research could have been further advanced than Riezler knew, but Allied bombing and work of (in German eyes) more military importance did not leave much opportunity for it.

What Klotz says is corroborated by Heisenberg in his paper in Die Naturwissenschaften about the German nuclear energy efforts during the war (p. 327): "Furthermore, it was to be expected that one can produce an explosive for atomic bombs in a uranium burner. [The term 'reactor' was not yet used, F.K.] However, no investigations about the technical side of the atomic bomb problem, e.g., about the minimum size of a bomb, had been made."

\section{Friedrich Katscher}

Mariahilfer Str. 133,

A-1150 Vienna,

Austria

\section{Pointed error}

SIR - I have often enjoyed Birch's satirical cartoons on topical scientific issues. He frequently includes clever symbols in his cartoons to emphasize his point. In the past few years, he has included the Saguaro cactus in drawings depicting events that have occurred in the Mojave Desert of California and in central New Mexico (Nature 364, 750; 1993 \& 377, 96; 1995).

Finding a Saguaro cactus in either of these locations would be a considerable range extension for this plant. The Saguaro cactus is endemic only to the North American Sonoran Desert. This limits its distribution in the United States to southern Arizona and extreme southeastern California. Saguaro cacti would not naturally be found in either of the locations where Birch has placed them.

Wayne A. Van Voorhies

Department of Molecular

and Cellular Biology,

University of Arizona,

Tucson,

Arizona 85721, USA

\section{Correspondence}

Letters submitted for Correspondence should be typed, double-spaced, on one side of the paper only, or e-mailed to nature@nature.com

\section{Dirac was not an "obdurate" atheist}

SIR - In a report of the unveiling of a plaque honouring P. A. M. Dirac in Westminster Abbey (Nature 378, 223; 1995), it is stated that he was an "obdurate atheist".

This may be true, but in an article entitled "The evolution of the physicist's picture of nature" (Scientific American 208, 45-53; 1963), Dirac said:

It seems to be one of the fundamental features of nature that fundamental physical laws are described in terms of a mathematical theory of great beauty and power, needing quite a high standard of mathematics for one to understand it. You may wonder: Why is nature constructed along these lines? One can only answer that our present knowledge seems to show that nature is so constructed. We simply have to accept it. One could perhaps describe the situation by saying that God is a mathematician of a very high order, and He used very advanced mathematics in constructing the universe."

This does not sound as if it was written by an atheist, at least not an "obdurate" one. Fernando Orrego

Faculty of Medicine,

Universidad de los Andes,

Casilla 20106 ,

Santiago 20,

Chile

\section{Bioterminology}

SIR - 'Bioterminology' exercised the minds of R. P. J. Swannell et al. and Calvin Dytham (Nature 378, 14; 1996). I offer solutions to both their problems.

The idea of reserving the term 'bioremediation' for those acts that aim to enhance the intrinsic biodegradation of contaminants (Swannell et al.) has my support. Licensing agencies would presumably like to pay particular attention to processes that depend on the addition of extrinsic biota, genetically manipulated or otherwise, and for this the term 'bioaugmentation' is appropriate.

As for the slowed increase in the rate of papers with "biodiversity" in the title (Dytham), those of us who turned our attention away from taxonomy in the past because of the indifference of funding agencies are embittered. I suppose we should now stop instructing our students to exterminate any specimens not described in the field course guide.

Alan J. McCarthy

Department of Genetics

and Biology,

University of Liverpool,

Liverpool L69 3BX, UK 